\title{
Joel R. Poinsett, primer viajero-diplomático anglosajón en México
}

Marcela Terrazas y Basante

IIH-UNAM

Se narran los pormenores de la visita de Poinsett a México realizada en 1822 y se analizan sus opiniones sobre el país.

$\mathrm{L}$

a Nueva España, vedada a la curiosidad y las ambiciones de las potencias extranjeras durante tres siglos de dominación hispana, abriǒ sus puertas a la mirada inquisitiva, y con frecuencia codiciosa, de incontables viajeros que vinieron a México, recién lograda su independencia de la metrópoli.

La joven república se descubrió en el momento en que las naciones europeas más avanzadas: Holanda, Francia e Inglaterra, se lanzaban en la vertiginosa carrera del industrialismo y la expansión mercantil, y en que Estados Unidos iniciaba su revolución en el mercado y transitaba con paso decidido por el sendero del expansionismo territorial. México se presentó entonces como un campo virgen en situación de saciar los apetitos mercantiles de las potencias transallánti. cas y los afanes expansivos de la Unión Americana. Tanto ésta como aquéllas, enviaron a Méxicouna pléyade de viajeros con el propósito de escudriñar su situación y sus potencialidades. Los numerosos relatos de esos viajeros son prueba fiel de la fiera competencia que se entabló entre las naciones que los enviaron, son también testimonio de la voluntad hegemónica de los países industriales europeos y de la pujante nación norteamericana, todos ellos deseosos de imponer su predominio en el pais. La literatura de los viajeros es asimismo un rico filón de donde es posible "sacar a la luz y reconstruir un primer bosquejo del 
ser mexicano histórico que se encuentra subsumido en tan vasto cuanto interesante material transeúnte y foráneo". ${ }^{1}$

Es desde luego comprensible la gran expectación que debió despertar en el mundo la independencia de los dominios españoles en América; también es lógico pensar que el interés norteamericano fuera particularmente mayor respecto a la nación vecina del sur. Esta atracción por México, sin embargo, no fue sólo producto de la mera curiosidad por una situación inédita; provino de la entraña de una nación cuyo impulso expansionista estaba en plena efervescencia y cuya idea de predestinación buscaba un ámbito donde concretarse.

Para realizar exitosamente estos proyectos, resultaba imperante tener una visión puntual de lo que México era y podía ofrecer; había que poner al día la versión que Humboldt ofreciera en 1808 en su conocidísimo Ensayo político; era preciso constatar y actualizar aquel inventario fabuloso de las riquezas mexicanas; urgía también adentrarse en la situación de su economía y de sus asuntos políticos, especialmente después de la devastadora guerra independentista, $y$ desde luego era necesario conocer los diversos estratos de la sociedad que poblaba la joven nación. Para eso vinieron a México numerosos viajeros, muchos de ellos anglosajones, durante las primeras décadas de vida independiente; éste fue también el propósito del viaje del primer viajero y diplomático anglosajón a México, Joel Roberts Poinsett.

Poinsett es, posiblemente, uno de los comisionados norteamericanos en México que ha despertado mayor interés entre estudiosos tanto norteamericanos como mexicanos; muchos son los historiadores y politólogos que se han encar-

\footnotetext{
${ }^{1}$ Ortega y Medina, Zaguán, 1987, p. 11.
}

gado de él; sin embargo sus estudios se han ocupado de Poinsett como ministro plenipotenciario en México entre 1825 y $1829^{2}$ básicamente, se ha atendido muy poco a su actuación como viajero en su primera visita a este país en 1822 , cuyos frutos principales serían las representaciones tempraneras de la nación recién independizada, destinadas al pueblo y al gobierno norteamericanos. ${ }^{3}$ Estas imágenes tratarían de moldear la opinión pública estadunidense y de orientar la visión del Estado norteamericano sobre sus vecinos. Aunque es dificil precisar en qué medida la versión de Poinsett sobre México influyó en la visión de la sociedad civil estadunidense, se conoce bien el hecho de que sus informes determinaron su elección como primer enviado extraordinario y plenipotenciario de Estados Unidos ante el gobierno mexicano. El propósito de las siguientes páginas es ocuparnos de esos primeros relatos.

Enviado por el Departamento de Estado norteamericano con el fin de informar sobre las condiciones imperantes en México después de la independencia, Poinsett recogió las impresiones de este viaje en dos libros: Notes on Mexico, 1822 y The present political State of Mexico. A previously unpublished report on the political condition of Mexico in 1822, prepared for the United States Secretary of State. El primero describe "para el pueblo estadunidense" aspectos de la sociedad, la cultura, y la economía mexicanas; el segundo contiene informes sobre la situación política de México en los albores de la vida independiente dirigidos a la secretaría de Estado norteamericana.

\footnotetext{
${ }^{2}$ Bosch García, Documentos, 1974; Callahan, American, 1967; Fuentes Mares, Poinsett, 1951; Mac Corkle, American, 1933; Manning, Early, 1968.

${ }^{3}$ Uno de los pocos historiadores que se han ocupado de este aspecto es Ortega y Medina, $\mathrm{Za}$ guân, 1987 y México, 1955, vol. II, p. 22.
} 


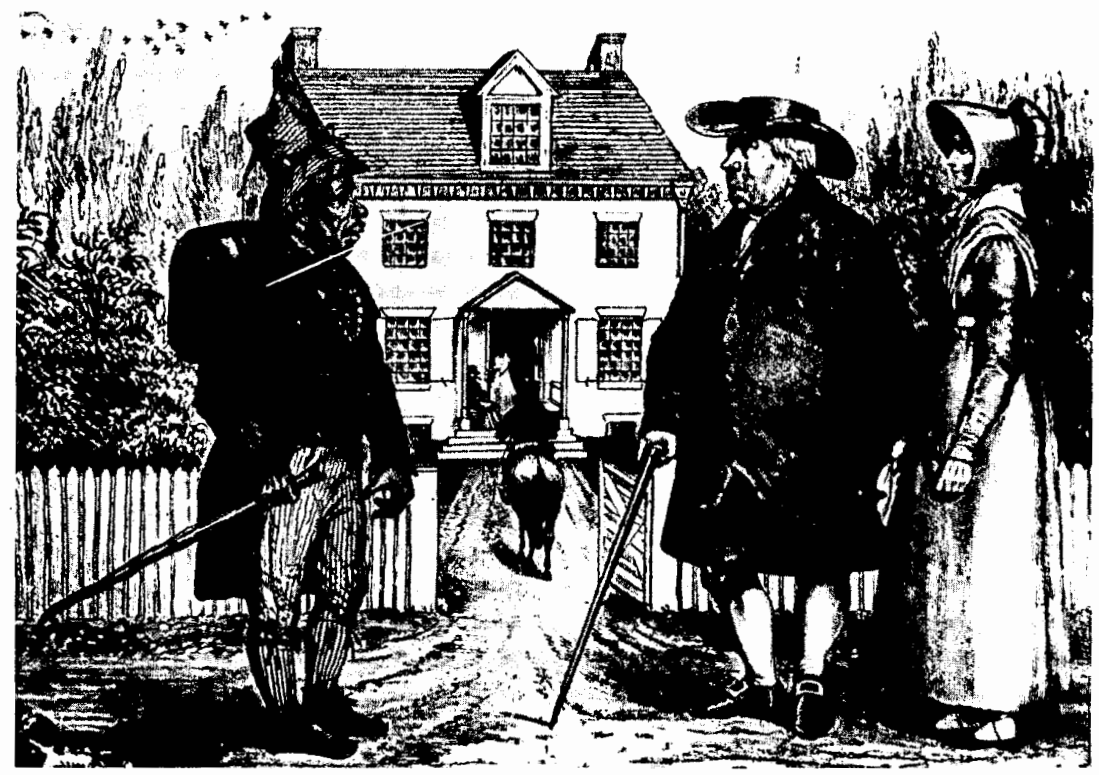

Notas sobre México (1822), fue publicado por vez primera en inglés, en Filadelfia en 1824. En esa ocasión la obra apareció en forma anónima firmada por "un ciudadano de Estados Unidos". Años más tarde, en 1825, el libro se reimprimió en Londres con el tutulo de: Notes on Mexico, made in the autumm of 1822. Accompanied by a historical sketch of the revolution and translations of official reports on the present state of that country. En esta segunda edición apareció ya el nombre del autor. La obra fue escrita según el propio Poinsett, durante su viaje a México en el otoño de 1822; eran "...cartas dirigidas a un amigo, sin el propósito de que vieran la luz pública". Según Poinsett, el profundo interés del pueblo estadunidense por todo lo relativo a México aunado a la imperfección de los relatos sobre este país y su reciente revolución, lo llevarian a darlas a la im- prenta. Añadió que Las notas..., a excepción del breve bosquejo histórico del apéndice, fueron escritas en sus ratos de ocio en la ciudad de México y durante su recorrido por el país.

Queda así esclarecido el asunto de la publicación de la obra. Lo que resulta menos claro es el hecho de que la primera edición no haya aparecido firmada. La naturaleza oscura de la verdadera misión de Poinsett, los sombríos designios de su viaje pueden posiblemente explicarnos el enigma. Como veremos más adelante, existen autores que consideran que los auténticos objetivos del viajero eran ampliar la extensión territorial norteamericana a costa de suelo mexicano en primer término, y terminar con el gobierno monárquico de Iturbide, en segundo. El epílogo de este capítulo tuvo lugar hasta la segunda misión de Poinsett en México. En ese momento la obra reco- 
gió en buena medida el pensamiento norteamericano sobre México, a la vez que lo orientó.

Antes de adentramos en los relatos de este primer viajero-diplomático norteamericano en México, valdría la pena bosquejar la figura del multimencionado personaje.

Datos biográficos de Joel Roberts Poinsett. Poinsett era descendiente de calvinistas franceses emigrados a América en 1685 al revocarse el edicto de Nantes. ${ }^{4}$ Su padre, médico de profesión, sirvió durante algún tiempo a la causa de la independencia de las colonias inglesas en América; más tarde juró fidelidad a la corona y vivió en Inglaterra con su familia entre 1782 y 1788.

Joel Roberts Poinsett nació en 1779 en Charleston, Carolina del Sur. Inició su preparación en Connecticut, y en 1796 viajó a Inglaterra para continuar sus estudios. Su frágil salud le hizo abandonar pronto la carrera de medicina que había emprendido en Escocia. Intentó más tarde seguir la preparación militar pero fue rechazado, por lo que decidió pagar un maestro particular que lo adiestrara en diversas materias relacionadas con esta actividad. Tampoco consiguió dar fin a sus estudios de abogacía y en 1801, a los 22 años, viajó nuevamente a Europa.

En la Francia napoleónica su casa se convirtió en centro de reunión de revolucionarios y bonapartistas. Anfitrión pródigo, excelente conversador, hombre

\footnotetext{
${ }^{4}$ El edicto de Nantes fue promulgado en 1598 por EnriqueIV, enfavor delos protestantes franceses. Cabe señalar que aun cuando étnicamente Poinsett pueda serconsideradomáscomogaloquecomoanglosajón, culturalmente se le deberá tener como un magnífico exponente de los valores anglosajones puritanos. Sobre la vida de Poinsett véase el bosquejo históricobiográfico de Eduardo Enrique Ríos en Poinsett, Notas, 1950.
}

ingenioso, atrajo la presencia de franceses ávidos de conocer de viva voz las experiencias republicanas de Estados Unidos de Norteamérica. Viajó más tarde por Suiza e Italia, conoció a Madame de Stael, ${ }^{5}$ y a Guillermo de Humboldt, hermano del famoso barón. Visitó también la capital del imperio austrohúngaro y refunfuñó por las incomodidades de las posadas vienesas, presagio de aquellas que tendría que visitar en México.

Poinsett heredó de su padre una fortuna considerable, 100000 pesos que gastó con mesura en nuevos viajes al norte de Estados Unidos, Suecia y Finlandia. En 1806 se presentó ante la corte del zar Alejandro cuando Napoleón se aprestaba para incursionar en Rusia. Su apasionada convicción republicana llevó a Poinsett a encomiar las instituciones liberales ante el zar, quien respondió: "Tiene usted razón señor, y si yo no fuera emperador, seguramente que sería republicano." 6

Viajero incansable recorrió el vasto imperio ruso, conoció Moscú, las playas del Caspio, el Cáucaso, y los dominios del khan de Kubán; llegó hasta Crimea, recorrió Ucrania y enfermo del hígado regresó a San Petesburgo en 1807, donde el ministro de Relaciones del zar pretendió que se le nombrara embajador en la corte imperial. Cuando las tensiones prebélicas entre Estados Unidos e Inglaterra se agudizaron, Poinsett retornó a su país.

El entomo internacional. En Estados Unidos, entretanto, elgobierno había dado un paso espectacular en su marcha expansionista al adquirir de Napoleón el territorio de la Luisiana con lo que llevaba sus fronteras hasta Nueva España y los dominios ingleses en el septentrión ame-

\footnotetext{
${ }^{5}$ Famosa escritora francesa hija de Nécker.

${ }^{6}$ Gaxiola, Poinsett, 1936, p. 26.
} 
ricano. Después de arreglar sus diferendos comerciales con Francia; y contando ya con un extenso territorio, las consignas nacionalistas y belicistas norteamericanas se hicieron una, exigiendo el enfrentamiento con la antigua metrópoli. Inglaterra había afectado seriamente importantes intereses estadunidenses al decretar las 24 ordenanzas que se proponían encauzar por sus puertos el comercio de los países que no participaban en las guerras contrarrevolucionarias. Los productores de tabaco, trigo y algodón de Estados Unidos resultaron perjudicados con las medidas británicas, al igual que otros productores agrícolas del oeste y del sur. Todos ellos demandaban la invasión del Canadá, y el empleo de buques corsarios, que obligarian al gobierno inglés a retractarse de las medidas impuestas y lo harían firmar la paz con soluciones satisfactorias a los intereses agrarios norteamericanos. La guerra serviría también para impedir que los indios de las regiones fronterizas del norte recibieran armas de ingleses y españoles, facilitando con ello su total sojuzgamiento. ${ }^{7}$ Los expansionistas exigían la ocupación de la Florida española so pretexto de impedir que los ingleses se apoderaran de ese territorio.

Hacia 1810, después de largas estancias en Europa, de haber sostenido estrechos contactosen la corte del zarAlejandro, de conocer el imperio austrohúngaro, de mantener estupendas relaciones en París, Poinsett era considerado en su país como uno de los mejores conocedores de los asuntos políticos europeos. Sabía de los proyectos ingleses y franceses en el continente americano en ese momento en que el monopolio comercial español sobre Hispanoamérica estaba a punto de derrumbarse y conocía la decisión del gobierno estadunidense de competir con

\footnotetext{
${ }^{7}$ La guerra estallo finalmente en 1812.
}

Inglaterra para establecer su hegemonía en el hemisferio.

Las naciones que nacieron en la América hispana surgieron vinculadas a una ideología liberal de la que Estados Unidos se consideraba la mejor expresión. Aun cuando las verdaderas raíces del liberalismo hispanoamericano se encuentran en la propia tradición liberal española que se manifestó con claridad en Cádiz, no podemos negar que las instituciones y las formas que adoptó el estado nacional estadunidense mucho influyeron en la formación de los nuevos estados americanos. No obstante este vínculo que estrechaba la relación entre Estados Unidos y los países americanos recién independizados de España, existian dos factores que los distanciaban: el problema fronterizo heredado del régimen colonial español y la necesidad de Estados Unidos de mantener sus lazos con Europa cuyos capitales, mercados y líneas de comunicación le eran indispensables. La Unión Americana deseaba penetrar en los mercados del hemisferio, siempre y cuando ellono implicara un enfrentamientobélico con las potencias europeas. En ese sentido el testamento político de Washington resultaba bastante claro: Estados Unidos debía desarrollar su economía, especialmente en el mercado externo, manteniendo una estricta neutralidad frente a los conflictos internacionales. En caso de necesidad extrema la nación podía establecer alianzas temporales, nunca permanentes. ${ }^{8}$ De manera tal que la vía para conciliar los intereses estadunidenses en América por una parte, y en Europa por la otra, resultó ser la Doctrina Monroe.?

Respecto a la cuestión fronteriza con la América española, bien vale la pena 55.

${ }^{8}$ Adams (comp.), Los Estados Unidos, 1980, p.

${ }^{9}$ Bosch García, Problemas, 1986, p. 8. 
detenerse brevemente en los antecedentes inmediatos, pues mucho ayudarán a explicar el asunto del que nos ocuparemos más tarde: el viaje de Poinsett a México. El problema surgió entre España y Estados Unidos por los límites de la Luisiana en la segunda década del xix. En tanto que los norteamericanos aseguraban que la Luisiana llegaba hasta el río Grande, como llamaban al Bravo, el ministro español Luis de Onís, afirmaba incluso que Texas se extendía hasta la cuenca del río Mississippi. Después de arduas negociaciones, los representantes de las dos naciones firmaron el Tratado OnísAdams en febrero de 1819 , donde se reconoció como lindero la desembocadura del río Sabinas. El pacto tardó dos años en ser ratificado y muy pronto en Estados Unidos surgieron las críticas al acuerdo que había renunciado a la po- sesión de la provincia texana. El propio presidente James Monroe, y el secretario de Estado John Q. Adams parecieron inclinados a abandonar el convenio esperando el fin de la dominación española en el continente. ${ }^{10}$ Entretanto las expediciones piráticas norteamericanas sobre las provincias del noreste novohispano mostraban el mismo afán expansionista expresado por la administración estadunidense. Finalmente el Onís-Adams fue ratificado en octubre de 1820 , cuando el levantamiento de Rafael de Riego había modificado la situación de España y sus colonias. Pocos meses después de publicarse el tratado, se consumaría la independencia de México.

Poinsett en el cono sur. En este contexto, Poinsett resultó ser el hombre

${ }^{10}$ Ibid., p. 14.

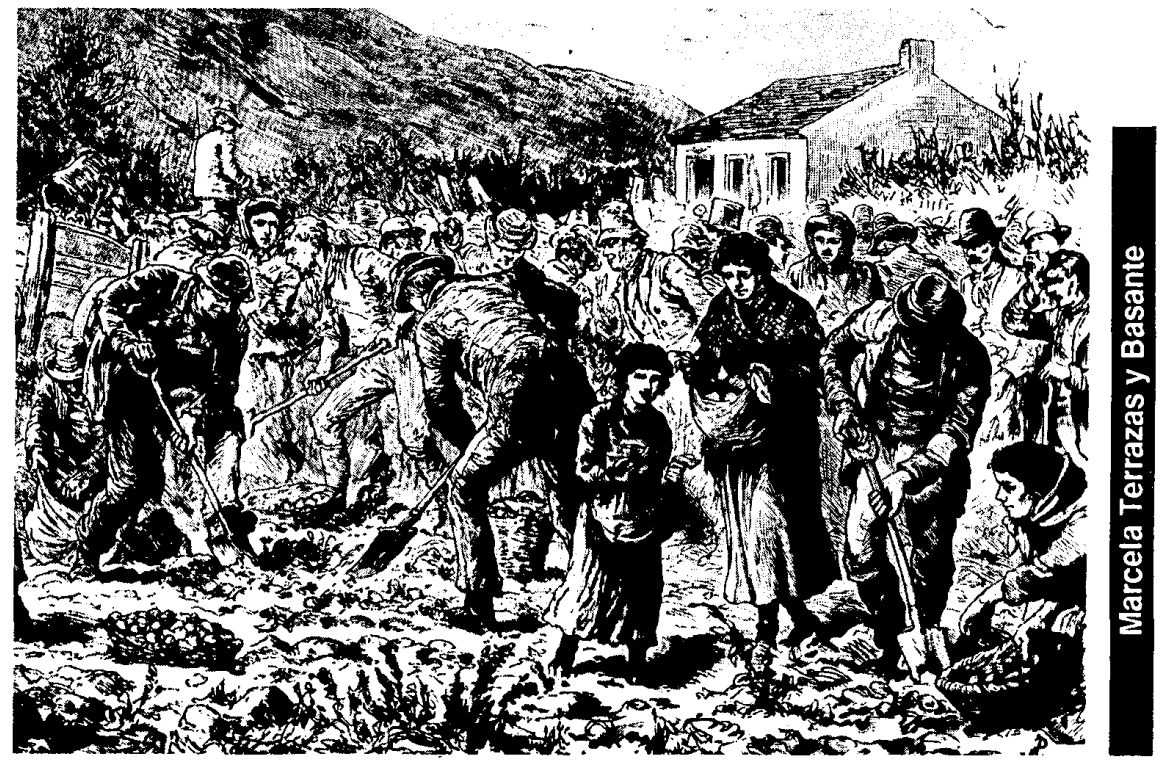


idóneo para la administración norteamericana, que requería de individuos hábiles para allegarse información y de observadores agudos que proporcionaran datos útiles sobre los dominios españoles. Reunía por su experiencia, capacidad de observación, sagacidad y reputación, atributos deseables en un enviado estadunidense a los países hispanoamericanos que habían comenzado sus luchas emancipadoras contra la metrópoli española. De ahí el nombramiento que le confirió el presidente Madison como agente comercial en Buenos Aires, donde se encargaría de persuadir a los insurgentes de las conveniencias derivadas de un tratado comercial con Estados Unidos. La misión de Poinsett era importante, delicada y desde luego secreta. Su país temía por entonces que Inglaterra se posesionara de Cuba y de la Florida española y con este pretexto decidió ocupar la península al finalizar el año de 1810.

Burlando la red de espionaje británica, Poinsett llegó a Buenos Aires, donde encontró que la influencia inglesa era demasiado fuerte para permitirle desarrollar su misión. Solicitó entonces a su gobierno una cartera menos limitada que aquélla de agente comercial, pero sólo consiguió que se le nombrara cónsul general en Buenos Aires, Chile y Perú. Con este nombramiento se dirigió a Chile con la esperanza de encontrar un campo de acción más propicio para su tarea. Llegó a Santiago pocos días después de la Nochebuena de 1811. Ahí trabó amistad con el líder José Miguel Carrera, que como otros próceres americanos, simpatizaba con Estados Unidos.

Las acciones de Poinsett en Chile parecieron exceder lo que sus instrucciones le demandaban. Ejerció un fuerte influjo en Carrera a quien sugirió enérgicas medidas en contra de los españo- les (como el cierre de los puertos al comercio con Perú), intentó infructuosamente allegar armas norteamericanas a los independentistas chilenos, y redactó un proyecto de constitución demasiado radical para el gusto de los chilenos moderados con quienes colaboró más tarde en la elaboración de una carta magna que se firmó en la propia residencia de Poinsett en Santiago. La intromisión del sureño llegó a ser tan ominosa, que provocó la división entre los mismos rebeldes chilenos, causando una ruptura temporal entre José Miguel Carrera, presidente de la Junta de Gobierno, y su hermano Juan José. Participó en la organización de cuerpos policiales, intervino en la elaboración de programas de intensificación de cultivos, promovió la fundación de un banco y asesoró a J. M. Carrera en asuntos militares. Su salida de Santiago fue consecuencia de la caída de su pupilo y del ascenso de Bernardo O'Higgins al poder; para entonces el descrédito de Poinsett era absoluto y la hostilidad promovida por los británicos en su contra determinó su partida de la nación andina en marzo de 1814.

En su país, entre 1815 y 1816 , Poinsett frecuentó a prominentes políticos: Henry Clay, Andrew Jackson, James Monroe. Este último le propuso una nueva misión en Sudamérica que el charlestoniano rechazó pues aspiraba a representar a Carolina del Sur en el Congreso. En 1821 logró su propósito, pero pocos meses después recibió instrucciones para una nueva misión; esta vez su destino era México.

Poinsett en México. Poinsett arribó a Veracruz el 18 de octubre de 1822. Ahí esperó noticias sobre la reacción que provocaría su llegada al comandante del puerto, Antonio López de Santa Anna. Los informes fueron favorables pues 
Santa Anna se dispuso a recibirlo y a darle una escolta que lo acompañara hasta la ciudad de México. Santa Anna había sido notificado por el ca pitán de la corbeta estadunidense de que el objetivo de Poinsett era entregar al emperador Iturbide pliegos de su gobierno de importancia para ambas naciones. En realidad los pliegos que Poinsett portaba no decían cosas de gran trascendencia; aunque las instrucciones escritas no lo señalaran, su misión sí tenía una enorme relevancia: Poinsett debía modificar la línea fronteriza trazada en el tratado Onís-Adams en 1819, de manera tal que "Texas, parte del reino de León, y de la provincia de Coahuila, la Sonora y California Baja, toda la Alta y el Nuevo México"11 pasaran a dominio norteamericano.

El relato que el viajero-diplomático nos ofrece en Notas sobre México se inició el 28 de agosto cuando Poinsett abordó en Charleston la corbeta John Adams, que lo llevaria, a su pesar, a Puerto Rico antes de dirigirse a Veracruz. Pocos días antes de llegar a costas mexicanas, la corbeta en que viajaba el norteamericano se topó con dos bergantines españoles, uno de los cuales transportaba al general Lemaur, quien iba a asumir el mando de San Juan de Ulúa. El 17 de octubre, un mes y 20 días después de haber zarpado, Poinsett se maravilló con el "magnífico panorama" de Veracruz.

El norteamericano encontró Veracruz en un extraño estado, ya que la ciudad estaba en manos del gobierno independiente, en tanto SanJuan de Ulúa obraba aún en poder de los españoles. Desde su llegada al puerto se ocupó diligentemente de indagar sobre las condiciones de la actividad comercial en México; los

"Poinsett, Notas, 1950, p. 20. aranceles, las alcabalas, las facilidades o riesgos para transportar las mercancías que provenian del exterior, topándose con un panorama ensombrecido por los numerosos gravámenes y una situación deplorable para el comercio, tanto "...por causa de los bandidos que infestan los caminos, como por la rapacidad del gobierno mismo". ${ }^{12}$

El comisionado visitó al coronel Santa Anna a quien describió como un hombre joven, bordeando los treinta, de complexión delgada pero simétrica y de fisonomía inteligente y expresiva, que le brindó una cordial acogida y le invitó a cenar, invitación que se empeñó inútilmente en rechazar, pues "una cena ceremoniosa española es para mí la más odiosa de todas las cosas". ${ }^{13}$

...lástima grande es que el coloquio de aquellos dos hombres no haya trascendido-dice el doctor Ortega y Medina-, el uno ardiente, conscientemente republicano e imperialista, el otro ardiendo en deseos de seralgo (pues noera sinoapenas nada, presunción de ser y voluntad ambiciosísima de llegar a serlo y para sí propio). ${ }^{14}$

Ciertamente una lástíma, pues algunos autores consideran que Poinsett influyó en Miguel Santa María, ministro de Colombia en México, y en Santa Anna, para que ambos participaran en el movimiento que puso fin al imperio de Iturbide. ${ }^{15}$ De acuerdo con Gaxiola, este es uno de los poco estudiados y principalísimos aspectos del viaje de Poinsett a México. De cualquier manera hay algo que sí es suficientemente claro en la frase del viajero de Carolina del Sur:

\footnotetext{
${ }^{12}$ Ibid., p. 51.

${ }^{13} \mathrm{Ibid}$. p. 52.

${ }^{14}$ Ortega y Medina, México, 1955, vol II, p. 22.

${ }^{15}$ Gaxiola, Poinsett, 1936, p. 32.
} 
desde que puso los pies en México, su rechazo a lo hispánico fue manifiesto.

Nuestro viandante encontró en Veracruz una ciudad pulcra y bien construida, aunque esta impresión positiva estuvo acompañada del temor que le provocaron los médanos que rodean la ciudad, donde se engendra el vómito negro y la fiebre biliosa, enfermedad aquélla, fatal para los forasteros. ${ }^{16}$ Poinsett se puso en camino hacia Jalapa, por Santa Fe y la finca azucarera de Paso de Ovejas, donde no dejó de observar los estragos que causó en esta última la guerra de Independencia, aún reciente. Observador atento, el sureño describió los bohíos o chozas que encontró a lo largo del trayecto, advirtiendo también las diferencias étnicas de los habitantes que "...exhiben todos los matices del color, desde el blanco hasta el negro". ${ }^{17}$

El sureño pasó las de Caín al llegar al Encero, donde una buena mujer le ofreció albergue en su propio lecho. Ahí, nutridos enjambres de pulgas, zancudos y moscos se encargaron de hacer de aquélla una noche fatalmente inolvidable para el norteamericano. En el fondo de todas estas quejas yace la visión compartida por los viajeros anglosajones que en el siglo xix estuvieron en México: una visión preñada del concepto de confort, peculiar de los anglosajones protestantes, que tiene que ver con su concepción de la riqueza y del uso de esa riqueza:

El hombre protestante anglosajón no es que desdeñase la riqueza, lo que le sacaba fuera de sí era el mal empleo y la ostentación de ésta; la prodigalidad y el derroche inútiles; la falta de un sano espíritu de

\footnotetext{
${ }^{16}$ Poinsett, Notas, 1950 , p. 33.

${ }^{17}$ Ibid., p. 62.
}

ahorro en todas las clases. Un vivir metódicosabiamente regulado (ingresos, egresos, ahorro); un vivir regulado, confortable, ahorrativo era su máxima aspiración; su vida debía transcurrir sencilla, limpia, higiénica, sin lujos desorbitados ni insultantes. ${ }^{18}$

A su llegada a Jalapa, el norteamericano entró a la ciudad por la calle de Pura sangre de Cristo, donde la sensibilidad protestante de nuestro viajero volvió a sentirse perturbada por aquel nombre impío. Afortunadamente para él, la naturaleza solía compensarlo de todos los sinsabores sufridos en este tortuoso viaje. A su salida de Jalapa, el viajero consignó:

...la vista [era] hermosísima, tan variada, lujuriosa y romántica que voy a agotar toda mi fraseología de lo pintoresco y aún asi no podré dar una idea de todas las bellezas del valle que se extiende a nuestros pies en donde se cultivan todas las frutas tropicales y que está salpicada de multitud de cerritos cónicos recubiertos de bosque hasta sus cimas. ${ }^{19}$

Las primeras quejas sobre el nuevo gobiemo llegaron a sus oídos en Tepeyehualco: provenían de una "gachupina" a cuya hospitalidad no pudo corresponder con un epíteto más amable. Aquí probó por vez primera el pulque, blanco y espumoso, del cual gustó, difiriendo en ello -ocasión excepcional- de la apreciación de Humboldt quien lo describiera con un sabor a carne descompuesta. ${ }^{20}$

En el trayecto hacia Puebla, el sureño observó el paisaje y lo describió detalladamente. Miró con cuidado el aspecto

\footnotetext{
${ }^{18}$ Ortega y Medina, México, 1955, vol. II, p. 70.

${ }^{19}$ Poinsett, Notas, 1950, p. 72.

${ }^{20} \mathrm{Ibid}$, p. 74
} 


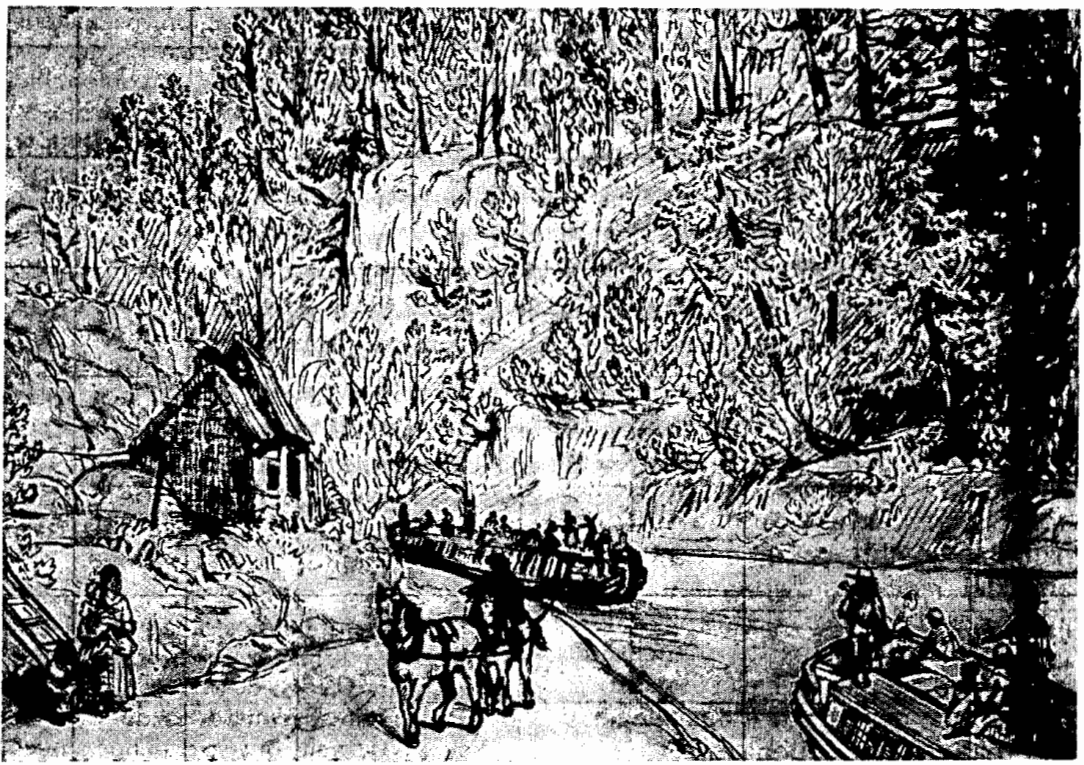

que ofrecía la tierra, cultivada o yerma, las herramientas de labranza que se utilizaban, se extasió con las maravillas que le mostraba la naturaleza:

...[el Popocatépetl] la montaña más soberana de América del Norte, aparece como un cono simétrico cubierto de nieve perpetua; se yergue a la altura estupenda de 17716 pies sobre el nivel del mar y de 11150 sobre la planicie que pisaban nuestras plantas. ${ }^{21}$

Ya en Puebla, Poinsett visitó la catedral. "El exterior no es muy notable", escribió, exhibiendo además de escasos conocimientos en arte, un prejuicio, "...una condena que en el fuero interno, íntimo de cada viajero no deja de ser teológico. ${ }^{n 2}$ Se trata en realidad de un

${ }^{21}$ Ibid., p. 80.

${ }^{22}$ Ortega y Medina, México, 1955, vol. II, p. 101. rechazo a la magnificencia de las catedrales, las iglesias y aun los templos católicos común a los viajeros anglosajones puritanos, y que mucho deriva del repudio a la

...riqueza improductiva, ávida, inútilmente suntuaria; una riqueza estancada viciosamente a la circulación mercantil y financiera; una riqueza estancada medieval y por consiguiente enemiga del victorioso y codicioso ascetismo intramundano de los tiempos modernos. ${ }^{24}$

El interior de la catedral de la Angelópolis mereció de Poinsett una opinión más favorable, y a su descripción dedicó un amplio espacio. Sin embargo junto a esta explicación encomiosa añađió: "En medio de todo este esplendor erraban

${ }^{23} \mathrm{Ibid}$. 
indios miserables y semidesnudos, que nos miraban boquiabiertos..., of reciendo un contraste tan singular como doloroso con el magnífico templo". ${ }^{24}$ El relato es en sí un claroscuro, una pintura contrastante que no oculta el rechazo del autor a lo que sus ojos observan. En las obras magníficas heredadas del periodo colonial encontró siempre un pero que empañaba su grandeza; especialmente si estas obras tenían que ver con la Iglesia católica, con el legado hispánico. En su mentalidad liberal y moderna, tan imbuida de la idea de progreso, de los valores del capitalismo, la mera existencia de una riqueza suntuaria y estéril parecía algo más que absurda.

Por otra parte la exhibición impúdica de aquellos indigentes, que por el mismo hecho de serlo mostraban su carâcter réprobo, provocaba en los puritanos un rechazo inconmensurable y dificil de ocultar. Puebla, que a los ojos de Poinsett era una ciudad bien trazada, con amplias y cómodas casas de piedra, ofrecía a la vez el deplorable espectáculo de la miseria. ${ }^{25}$ Esta disparidad apareció repetidamente ante los ojos del estadunidense, provocando un terrible malestar. Tal realidad aberrante sólo podía explicarse -pensó Poinsett- gracias al clima benigno y a la fertilidad del suelo que "...premia abundantemente el esfuerzo moderado... En los países como éste, el pueblo rara vez acostumbra ser industrioso. La gente sólo trabaja lo precisamente indispensable para vivir y pasársela de manos a boca". ${ }^{26}$ El juicio resumía todo un sistema de valores propio del liberal decimonónico, del protestante calvinista, para quien el trabajo fecundo, especialmente el redi- tuable y exitoso era marca de la elección divina y del éxito social; pruebas de estar en el camino de la gloria y la modernidad capitalista. Por estas mismas razones, el norteamericano observó con desprecio las instituciones de caridad, ${ }^{27}$ resabios feudales e hispanizantes que corrompían al hombre.

Poinsett señaló que en Puebla trataron de convencerle de que Iturbide había sido elevado al trono por la voluntad unánime del pueblo, cosa que nunca creyó pues, "...que [un pueblo] se conforme con vivir bajo un gobierno arbitrario inmediatamente después del triunfo de una revolución, me parece de lo más extraño"; ${ }^{28}$ y no podía ser de otra manera para un convencido defensor de las extraordinarias virtudes del sistema republicano. Poinsett dificilmente podía entender que una nación recién independizada de "la tiranía hispánica" no adoptase las formas de gobierno que su vecino del norte ostentaba como la fórmula perfecta para manejar los asuntos del gobierno: la república federada. Este prejuicio lo acompañó en su primer y segundo viaje a México y fue en buena medida el origen de su incomprensión, sus opiniones prejuiciadas y la razón de su conducta en México.

A las puertas de la ciudad de México nuestro viajero observó:

La apariencia de la ciudad a esta distancia [que] prometía una ciudad grande y bien construida. Las ciudades católicas tienen ciertas ventajas sobre las nuestras por el tamaño y esplendor de sus templos y la cantidad de torres y cúpulas que las adornan. A alguna distancia, México supera cualquier otra ciudad de América del Norte. $^{29}$

\footnotetext{
${ }^{27}$ Ibid.

${ }^{28} \mathrm{Ibid}$., p. 85.

${ }^{29}$ Tbid., p. 91.
}

${ }^{25}$ Ibid. P. 84.

${ }^{26}$ Ibid. 
Empero esta primera impresión favorable desvanecióse fácilmente a la caída de la lluvia y al paso por los suburbios que "...son muy asquerosos y las casas bajas construidas de lodo y adobe... ${ }^{n 0}$ Como en Puebla, Poinsett no pudo dejar de reconocer la magnificencia de la capital mexicana, su aspecto de solidez, su aire de grandeza, ausente en las ciudades de Estados Unidos; pero-y aquí está el infaltable pero- "...entre nosotros el forastero no ve ese sorprendente y asqueroso contraste entre el esplendor de los ricos y la escuálida penuria de los pobres que continuamente hiere sus ojos en México". ${ }^{31}$

En la capital mexicana el incansable viajero, ávido de conocer todo cuanto el tiempo y su infatigable ánimo le permitieran, visitó el mercado, la Alameda, los acueductos, el palacio de los virreyes, la catedral, la estatua de Carlos IV, la casa del conde de Regla, el Paseo Nuevo, la casa del Apartado, la de Moneda. En el mercado se sorprendió con la gran variedad de comestibles que ahi se vendían, pero sobre todo con la abundante caza: patos silvestres, aves de distintas clases, venado, liebre y una extraordinaria variedad de frutas y legumbres, que "...excedian de lo que viera jamás en mercado alguno de Europa o América". ${ }^{32}$ En las numerosas visitas sociales que realizó, Poinsett no dejó de asombrarse ante la presencia de damas fumadoras que con gran desenvoltura disfrutaban del placer del tabaco, lo que a los ojos de nuestro frugal viajero resultaba realmente detestable. ${ }^{33}$ De igual manera las tertulias donde las jóvenes cantaban, bailaban, y participaban en los juegos de azar, no dejaron de parecer reprobables a la conciencia

\footnotetext{
30 Ibid., p. 92.

${ }^{31}$ Ibid., pp. 94-95.

${ }^{32}$ Ibid., pp. 95-96.

${ }^{33} \mathrm{Ibid}$., pp. 105-106.
}

puritana del norteamericano que no alcanzaba a comprender estas expresiones

...que antojábansele absurdas y condenatorias, antiprogresistas y antieconómicas (derroche de tiempo y esfuerzos infructuosos)... señal segura del anómalo contraste que presentaba nuestro mundo [hispanoamericano] frente al suyo tan activo y laborioso. ${ }^{34}$

Parte de este mundo impenetrable para el norteamericano la constituía la cortesía hispana:

He dedicado gran parte de este día que es fiesta de Todos Santos a hacer o más bien devolver, visitas ceremoniosas. Sir Archy puede haberse inclinado más hacia tierra pero no más frecuentemente que yo en este día. Acordaos cuando os despedís de un grande de España, de hacer una reverencia al salir del aposento, otra a la cabeza de la escalera, a donde os acompaña el anfitrión, y después de bajar el primer tramo voltead y lo veréis parado en espera de un tercer saludo, que devuelve con gran cortesía y ahí se queda hasta que đesaparecéis de su vista; de modo que al seguir bajando la escalera, si lo entrevéis una vez más, enviadle un beso con la mano y os tendrá por un caballero harto cumplido. ${ }^{35}$

Estando en la capital, el enviado norteamericano tuvo noticias de la disolución del Congreso. A poco, Poinsett visitó a los presos políticos con quienes conversó. Fagoaga, Tagle y Herrera pareciéronle hombres bien educados $e$ informados que encabezaban la oposición en el Congreso, impugnando la política arbitraria del emperador. ${ }^{36}$ En contraste con sus simpatías por los opositores del régimen imperial, la impresión que le

\footnotetext{
${ }^{34}$ Ortega y Medina, México, 1955, vol. II, p. 54. 35 Poinsett, Notas, 1950, p. 112.

${ }^{36}$ Ibid., p. 114.
} 


\section{SECUENCIA}

causó Iturbide se resumió en los siguientes párrafos:

su estatura es de unos cinco pies y diez o doce pulgadas, es de complexiôn robusta y bien porporcionado; su cara es ovalada y sus facciones son muy buenas excepto los ojos que siempre miran hacia abajo o para otro lado. ${ }^{37}$
Más adelante Poinsett recordó la crueldad de Iturbide con los insurgentes, y afirmó que se hizo notar por su inmoralidad en una sociedad que no se distinguía por su estricta moral. ${ }^{38}$

De trato agradable y simpático, y gracias a una prodigalidad desmedida, ha atraído

${ }^{37} \mathrm{Ibid}$, p. 116.

${ }^{39}$ Ibid., pp. 116-117.

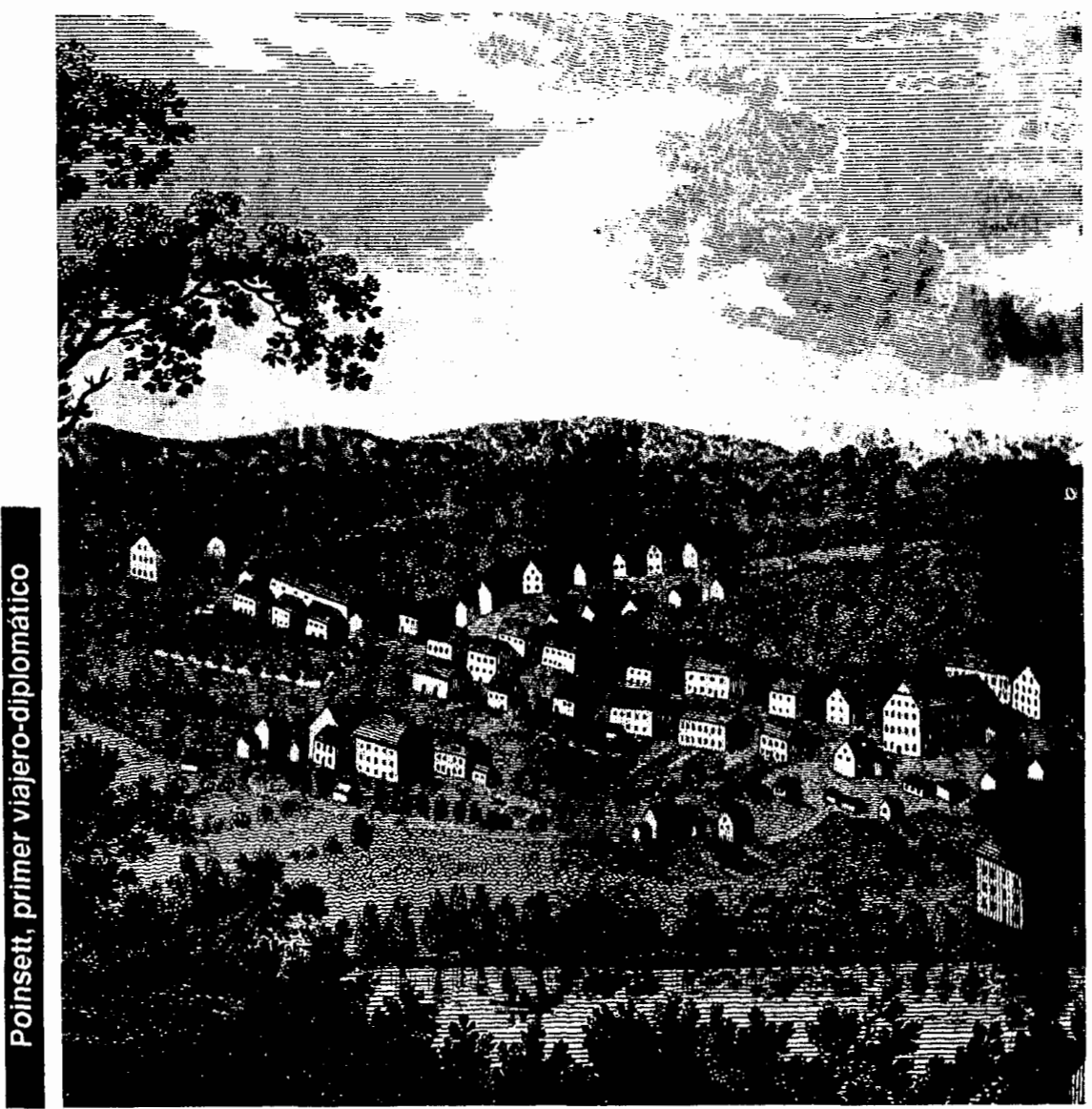


a los jefes oficiales y soldados a su persona, y mientras disponga de los medios de pagarles y recompensarles se sostendrá en el trono. Cuando le falten esos medios, lo arrojarán de él. Es máxima de la historia que un gobierno que no está fundado en la opinión pública, no puede existir sin amplios recursos para pagar a la soldadesca y para mantener a sus pensionados y partidarios, ${ }^{39}$

sentenció el incansable defensor de las instituciones republicanas, con gran desprecio por otra forma política que no fuera la que él profesaba.

Estas profundas convicciones liberales parecieron mover la preocupación de Poinsett quien encontró que los gobiemos de Hispanoamérica tenían una marcada tendencia en favor de Gran Bretaña. ${ }^{40} \mathrm{El}$ viajero-diplomático no dejó de señalar las iniquidades de gobiernos monárquicos que como el de Iturbide no representaban el sentir de sus pueblos, especialmente en este caso donde el norteamericano percibió, aunque no especifica dónde, la preferencia y simpatía popular de los mexicanos hacia los norteamericanos.

Poinsett escudriñó las posibilidades del comercio entre México y Estados Unidos. ${ }^{41}$ Para ello se basó en los datos del Ensayo político sobre el reino de la Nueva España, cuyos cuadros reprodujo a menudo. Tempranamente fijó codicioso sus ojos en Tehuantepec; esta avaricia habría de perdurar a lo largo de muchas décadas del siglo xIX; consideró asimismola amplitud del puerto de Coatzacoalcos que serviría para la comunicación interoceánica. Su ávida mirada no dejó de fijarse en el puerto de Acapulco, hasta ese momento desaprovechado para el

39 Ibid.

${ }^{40}$ Ibid., p. 118.

${ }^{41}$ Ibid., pp. 150-151. comercio. Observó también el estado de las manufacturas mexicanas, cuya producción estimó en 7 u 8000000 anuales, siempre basado en Humboldt. Pero el área de producción que más le ocupó fue naturalmente la minería, donde encontró un panorama desalentador:

El agua invade más y más cada día las labores de las minas; los caminos se han vuelto más inseguros; la confianza del público en la buena fe del gobiemo se ha quebrantado y el minero ya no puede como antes percibir inmediatamente el valor de la plata que deposita en la casa de moneda...En el estado actual del país, las minas tienen que permanecer relativamente improductivas. ${ }^{42}$

El autor dedicó numerosas páginas a la cuestión minera y reprodujo los datos de Humboldt sobre los ingresos que proporcionó esta actividad en 1803. Esta cifra serviría para estimular la codicia de los convencidos del destino manifiesto y dueños de la fórmula perfecta de gobierno que no vacilarían en extender el área de la libertad y la democracia a estas ricas tierras mineras.

El viajero se preocupó también por describir los grupos diversos que integraban la sociedad del México recién independizado. En los indios observó "...la misma indolencia, la misma sumisión a sus superiores e igual miseria abyecta",43 en resumen un grupo cuya situación no había cambiado esencialmente después de la independencia. Su desprecio hacia ellos era manifiesto y sus formas religiosas sincréticas le provocaron un profundo rechazo, los consideraba un pueblo oprimido y pisoteado desde antes de la conquista, e implícitamente incapaz para formas superiores de organización y go-

\footnotetext{
${ }^{42}$ Ibid., p. 161.

${ }^{43} \mathrm{Ibid}$., p. 178.
} 
bierno como sería la democracia representativa. Los indios de México, al igual que los de Estados Unidos, mantenían sus tierras estériles, afirmación que nos deriva fácilmente a la idea predestinatoria del uso del suelo: Dios había creado los suelos para ser trabajados, y si aquellos seres infelices no sabían hacerlo, no tenían derecho de ocuparlos.

$\mathrm{Al}$ igual que los indios, las castas eran pobres e indolentes; su condición permaneció inalterada después de la guerra independentista. "Es necesario educarlos y distribuir tierras entre ellos, antes de que se puedan considerar como parte de un pueblo que vive bajo un régimen de libertad" ${ }^{44}$ consideró este apóstol de la democracia de los propietarios para quien las formas comunales de propiedad, seguramente no constituian una garantía de ciudadanía respetable.

En los miembros de la nobleza, Poinsett encontró un claro resabio de la sociedad estamental, católica, papista, e hispánica

...felices en la posesión de amplias haciendas y con la consideración que les confieren sus riquezas y rango, no buscan otras distinciones. No se distinguen ni por sus conocimientos ni por la moralidad estricta de sus costumbres. ${ }^{45}$

Nuestro personaje se expresó con mayor indulgencia acerca de la clase trabajadora,

...incluye a la gente de todas las castas y colores; es industriosa y amante del orden y se fija con interés en lo que sucede a su alrededor... La clase trabajadora del campo, a semejanza de la anterior está formada por distintas castas. Son los campesinos, sobrios e industriosos, dóciles, ignorantes

44 Ibid., p. 179.

${ }^{45}$ Ibid, p. 180. y supersticiosos y dejan que sus sacerdotes o amos los manejen para bien o para $\mathrm{mal}^{45}$

Añadió que estos jornaleros que carecían de tierra y por tanto de apego a ella no se interesaban por la conservación de sus derechos civiles. Con esta observación confirmó Poinsett su visión de la democracia de propietarios compartida por un viejo conocido suyo: Andrew Jackson.

Finalmente, el autor se refirió a la última de las clases,

...desconocida como tal en una sociedad bien organizada, consiste en los mendigos y ociosos, zánganos que se mantienen a expensas de la colectividad y que no teniendo nada que perder están siempre prestos a engrosar el grito de la agitación popular o a prestar ayuda a la tiranía imperial. Las influencias de esta clase, cuando es numerosa, deciden la suerte de las revoluciones y siempre ha sido destructora de la libertad. ${ }^{47}$

Poinsett observó con rechazo la ilimitada influencia del clero sobre la sociedad mexicana. Pensó que los sacerdotes, salvo excepciones, se oponían a las libertades civiles. ${ }^{48}$ Pero este rasgo no era exclusivo del hombre de Charleston, en general, los viajeros anglosajones encontraron incompatibles los principios ilustrados, liberales y democráticos con aquéllos heredados del catolicismo. ${ }^{49}$

La descripción de los caracteres sociales de la población mexicana, así como los de la situación política del país, fueron indudablemente dos de los principales objetivos del periplo de Poinsett en

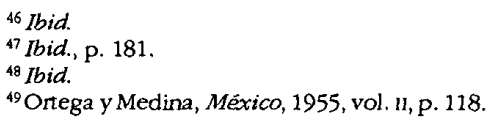




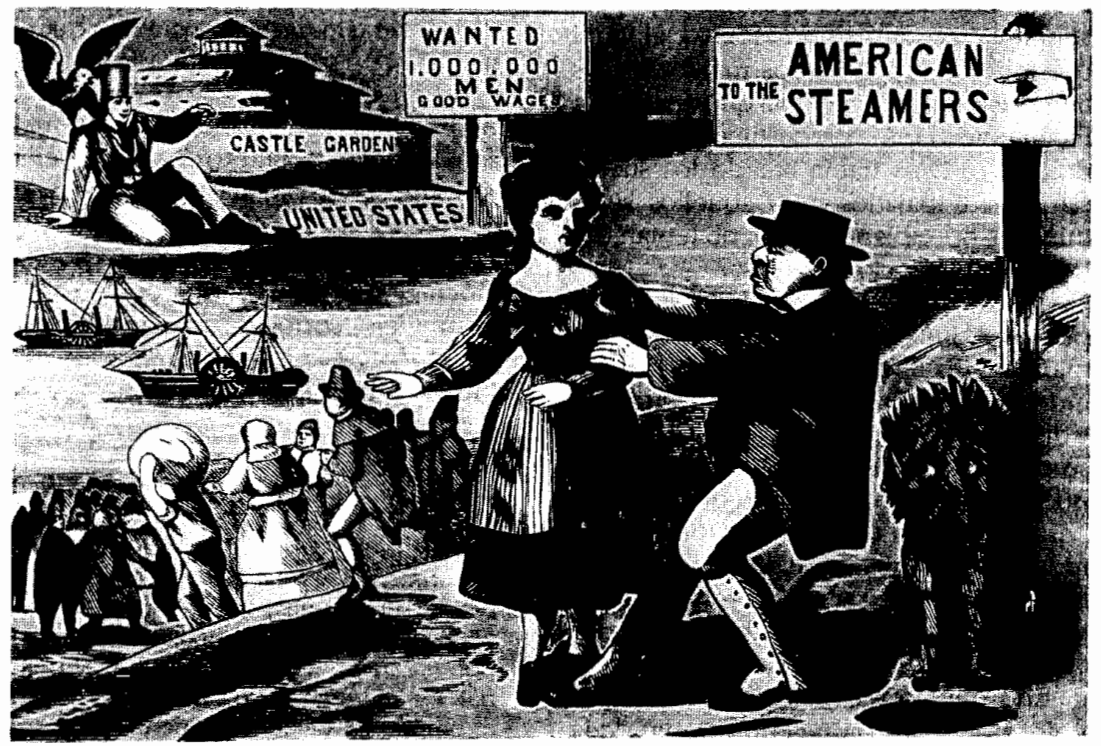

México; el otro lo fue la reseña de los recursos materiales de su territorio. En tal sentido su estancia en Guanajuato representó la culminación de su recorrido por México. Ahí el charlestoniano visitó los minerales y obtuvo del administrador de la Valenciana cuantos informes y mapas solicitó; recorrió las galerías de la mina, escudriñó los rumbos de los tiros y las labores internas, gracias a la buena disposición, desprendimiento $e$ ingenuidad con que se ofreció al extranjero una idea por demás clara de la riqueza de las entrañas de la tierra mexicana. Ello nos habla por una parté del carácter generoso de sus habitantes, pero por otra parte nos hace pensar que la difícil situación que enfrentó la minería mexicana después de la independencia llevaba a la urgencia de atraer capitales foráneos.
El espíritu previsor y pragmático de nuestro viajero, muy a tono con la idiosincrasia protestante puritana, le hizo recoger una inmensa cantidad de datos sobre la industria minera mexicana: procesos para extraer el mineral y su composición, cifras de los censos levantados en 1822 acerca de las minas, descripciones sobre haciendas de plata, y molinos del mineral, método del apartado, informes sobre costos de obras, de salarios y de la deplorable situación de las minas:

No puede existir duda alguna acerca de la posibilidad de aumentar considerablemente el producto de las minas de México. La libre importación del azogue y la reducción de los derechos y cargas que gravitan sobre la acuñación, contribuirán poderosamente a producir este efecto. Es 
imposible predecir el desarrollo que alcanzaría la extracción de minerales preciosos, bajo un régimen que inspirase confianza y diese amplia seguridad a los créditos. ${ }^{50}$

El liberalismo económico de Poinsett se trasluce claramente en estas frases; también se percibe en ellas su juicio condenatorio hacia el régimen monárquico que frenaba el libre desarrollo de una empresa tan rica y promisoria. No es difícil imaginar cuál era el régimen que según él inspiraría confianza y daría amplias seguridades a los créditos.

El recorrido del norteamericano prosiguió en dirección a San Luis Potosî y de ahí hacia Tampico. La travesía se volvió harto fatigosa: el calor intenso, el polvo, el viento del norte que azotaba con violencia las regiones por donde atravesaba, aumentaron la nostalgia por su país conforme se acercaba el fin del camino:

Nos regocijamos de que nuestro viaje haya terminado, pues llovió sin cesar en la noche, llueve todo el día. Nuestra ropa está húmeda, nuestro cuarto está cubierto de lodo y nos sentimos tristes y desamparados... Aquíprevalecen las fiebres biliosas... he despachado un correo a Tampico con instrucciones de que se nos avise tanluego comola corbeta que nos llevará de regreso a Estados Unidos sea avistada frente a la costa. ${ }^{51}$

Ésta fue la imagen sobre México que Poinsett pintó para sus conciudadanos. En ella dibujó la tierra, las gentes, la riqueza, el sistema político de la nueva nación según su muy particular perspectiva que, no obstante las singularidades que le imprimió el personaje, tenía la carga histórico-cultural de un norteamericano de su momento. Éste fue el

${ }^{50}$ Poinsett, Notas, 1950 , p. 240.

s1 Ibid., p. 273. primer retrato que el pueblo estadunidense tuvo de la joven nación vecina recién independizada, en el periodo preconstitucional y bajo una monarquỉa criolla. En esencia no era distinto del que ofreció al Departamento de Estado de Estados Unidos.

Sin embargo si hubo alguna diferencia entre las dos representaciones, estribó en el acento político que el autor dio a la segunda. En ella nuestro viajero puso ënfasis en las instituciones de poder y en la organización que en México se dio después de los Tratados de Córdoba.

Poinsett advirtió a su gobierno sobre la influencia desmedida del alto clero en la nueva administración de México. Describió los sectores que llevaron a Agustín de Iturbide al trono y sus propósitos; habló del establecimiento de la Regencia, a cuya cabeza se encontraba Iturbide, y observó con manifiesto rechazo el excesivo poder que, según su republicano y federal juicio, detentaba el generalísimo. ${ }^{52}$

El enviado de Washington puso especial cuidado en relatar a su gobierno las dificultades que enfrentaban al Congreso con Iturbide y la forma irregular en que los miembros de aquél fueron electos por la Junta Gubernativa, asimismo habló sobre la avidez de la población de México por tener un gobierno representativo; ${ }^{53}$ tenía ante sí un gobierno parlamentario, pero lo juzgó lleno de imperfecciones y muy lejos del paradigma republicano de Estados Unidos, por lo cual afirmó siempre que pudo las ansias democráticas de la población mexicana.

s2 Poinsett, Present, 1976, p. 25.

$\$ 3$ Poinsett escribió a su gobierno: “... aunque la gente no aprobó completamente el modo en que la Junta Gubernativa eligió a los diputados, ellos estaban tan ansiosos de estar representados en un congreso, que las elecciones se llevaron a cabo inmediatamente", ibid., p. 28. 
Poinsett informó al secretario de Estado acerca de la crisis entre el emperador y el Congreso, y el descontento manifiesto en contra de Iturbide:

Es imposible formarse una opinión correcta de lo que puede ser el resultado de este enfrentamiento, pero se hace imposible dejar de preguntarse qué tan justo o político es sancionar la usurpación y reconocer como legítimo a un gobierno erigido y apoyado en la violencia y opresión. Al reconocer al emperador en la presente disputa le hemos dado ventaja sobre el partido republicano. Hemos tomado partido contra la mayoría de la nación, no me atrevería a afirmar que el pueblo mexicano fue mas unánime en la declaración de independencia, que lo es ahora en favor del establecimiento de un gobierno republicano liberal y constitucional. $^{54}$

Conclusiones. La auténtica etapa diplomática, viajera y anglosajona se inaugura de hecho con Poinsett, nos dice Ortega y Medina.$^{55}$ Este viajero y diplomático a la vez, llegó a México como tantos otros, vestido indefectiblemente con el ropaje de su bagaje cultural, de su historia personal, del atuendo que su entorno inmediato ayudó a configurar. Vino también delimitado por el contexto histórico mundial que en mayor o menor medida marca el rumbo general de las naciones; arribó a tierras mexicanas sellado por la historia pasada y presente de la nación a la que pertenecía y en su peregrinar por un país extraño recibió el impacto de una realidad nueva y distinta, que debió confrontar con la imagen que de dicho país se había forjado.

El bagaje de Poinsett estaba constituido por varios elementos: se trataba de un

\footnotetext{
SA Ibid.

"5s Ortega y Medina, México, 1955.
}

descendiente de hugonotes emigrados a América, un protestante puritano que se asumía plenamente como tal y que por ende tenía una perspectiva del mundo empapada de la visión reformada. Al igual que la de los ingleses en los tres siglos anteriores, su opinión estuvo sobrecargada por el conflicto tricenturial entre el misoneísmo hispanocatólico y la modernidad protestante anglosajona, de suerte tal que no debemos sorprendernos del juicio implacable que lanzó sobre la sociedad a la que llegó y de la incomprensión que mostró ante el mundo que encontró.

Los valores que portaba nuestro viajero-diplomático chocaron con un universo que percibió papista, satánico e irremediablemente hispánico. Finalmente, el encuentro, o más bien el desencuentro con el mundo hispanoamericano, y en este caso con México particularmente, no modificó sustancialmente los arraigados prejuicios; más bien los confirmó convirtiéndolos en juicios. Su experiencia en el suelo mexicano no transformó su apreciación negativa sobre este país, más bien la reafirmó.

Las críticas hacia la indolencia, la holgazanería, la falta de empuje industrioso que advirtió en prácticamente todos los componentes de la sociedad mexicana; los ataques al despilfarro, al gasto suntuario, a la ostentación de la mayor parte de los mexicanos, tienen el sello de la idiosincrasia calvinista puritana que profesa la fe de la productividad, del lucro, del capital. Sus ataques a la iglesia católica, al oscurantismo con que la asocia tienen asimismo un claro origen protestante. El viajero, que llegó con el libro de Humboldt bajo el brazo, y con la visión paradisiaca y extraordinariamente promisoria del universo novohispano quedó desencantado al encontrar en este nuevo mundo americano el estigma de lo 
español y lo católico, de lo monárquico y lo retardatario. Poinsett no alcanzó a comprender cómo este universo nuevo pertenecía a los herederos de los anticristos españoles, que no habían sabido desembarazarse del funesto atavismo. No es difícil pensar cómo estos juicios se engarzaron con las convicciones predestinatorias y monroístas de un calvinista.

Pero a estos vigorosos elementos que Poinsett cargaba en su equipaje, debemos sumar otros más singulares. No podemos dejar de considerar que Poinsett era, después de todo, un sureño de posiciôn acomodada, que cultivó la amistad de políticos como Jackson, o el propio Monroe. Compartió con ellos la idea de extender las fronteras de su nación, y a eso vino a México. Creía firmemente en las instituciones liberales y republicanas y pensaba que la democracia sólo podía existir entre los propietarios; esta convicción le hizo desesperar con la gran masa de indios y castas desposeídas. Encontró muchos obstáculos para el avance del liberalismo en México, y en ese momento- el principal estorbo era, por supuesto, el régimen monárquico. Nunca entendió cómo una nación que había luchado por dar fin a un gobierno monárquico estableciera otro régimen monárquico. Pero como pragmático que ra, Poinsett no se detuvo ante un fenómeno que no pudo penetrar, y se dispuso a modificarlo con ánimo decidido. Gaxiola presume que el verdadero propósito de este primer viaje de Poinsett a México fue la ampliación de los linderos norteamericanos y el establecimiento de un régimen republicano. Aunque la obra inconclusa de Poinsett no haya llevado a buen término tales sospechas, su actua-

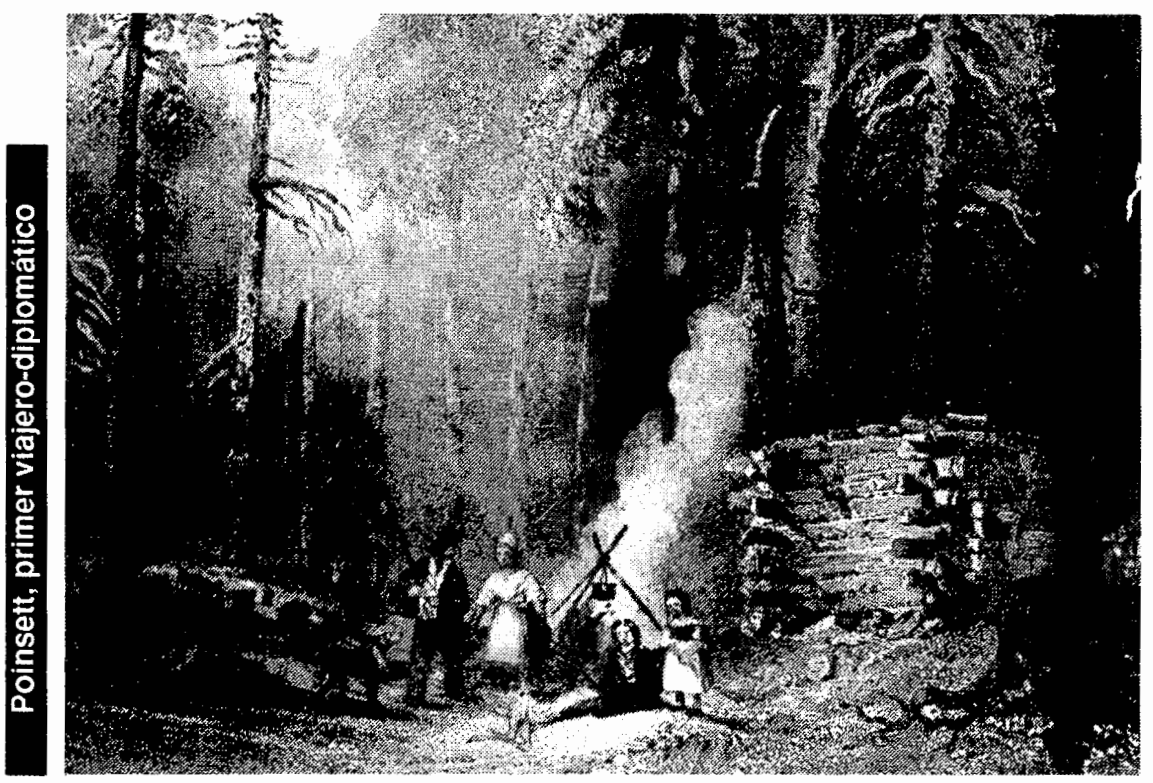


ción tanto en el primero como en el segundo viaje lo confirmaron.

No podemos dejar de considerar que la rivalidad norteamericano-británica por el dominio de las nuevas naciones hispanoamericanas estableció una de las líneas principales de la misión de Poinsett en México: el viajero y diplomático debía evitar la creciente influencia inglesa en los países recién independizados de España y abonar el terreno para un ascendiente norteamericano cada vez mayor. Al mismo tiempo debería observar la condición del país del sur: su situación política, su sociedad y desde luego el estado de su economía y la magnitud de sus riquezas naturales. Este último aspecto, fue, de todos, el que más lo sedujo. Por esta razón, al toparse con un México monárquico, hispanizado, católico y contrario al progreso y a las instituciones liberales más perfectas, se decepcionó profundamente. Su espíritu pragmático se impuso entonces y lollevó a actuar para modificar esa situación. Éste fue el objetivo de su segundo viaje a México, ya para entonces en calidad de ministro plenipotenciario.

La estancia del primer viajero y diplomático anglosajón en México dio como fruto las dos obras de las que aquí nos hemos ocupado; una, destinada a formar en el público estadunidense una imagen puntual de la cercana y joven nación que recién se abría al mundo; la otra dirigida a informar al gobierno de Estados Unidos sobre la condición del país del sur. Ambas serian la primera. estampa que los norteamericanos tendrían de sus vecinos después que hubieron alcanzado la independencia, pero finalmente estos dos libros nos dieron entre líneas el retrato de su autor, de la sociedad de la cual provenía y de los designios políticos de su gobierno.

\section{Bibliografía}

-Bosch García, Carlos, Documentos de la relación de México con los Estados Unidos (noviembre de 1824-diciembre de 1829), UNAM, México, 1983.

Problemas diplomáticos del México independiente, UNAM, México, 1986.

-Callahan, James Morton, American foreign policy in mexican relations, Cooper Square Publishers, Inc., Nueva York, 1967.

-Fuentes Mares, José, Poinsett. Historia de una gran intriga, Editorial Jus, México, 1951.

-Gaxiola, Francisco Javier, Poinsett en México (1822-1828). Notas a un libro inconcluso, Editorial Cultura, México, 1936.

-Mac Corkle, Alexander Stuart, American policy of recognition towards Mexico, The John Hopkins Press, Baltimore, 1933.

-Manning, William R., Early diplomatic relations between the United States and Mexico, Greenwood Press, Nueva York, 1968.

- Ortega y Medina, Juan Antonio, Méxicoen la conciencia anglosajona, 2 vols., Antigua Librería Robredo, México, 1955 (México y lo mexicano, 22).

Zaguán abierto al México republicano (1820-1830), Instituto de Investigaciones Históricas, UNAM, 1987 (Serie Historia Moderna y Contemporánea).

-Poinsett, Joel Roberts, Notas sobre México (1822), prólogo y notas de Eduardo Enrique Ríos, Editorial Jus, México, 1950.

The present political state of Mexico. A previously unpublisbed report on the political condition of Mexico in.1922 prepared for the United States Secretary of State, introducción y edición de L. Smith Lee, Documentary Publications, Salisbury, 1976. 